\title{
Integrated Nanofiltration and Upflow Anaerobic Sludge Blanket Treatment of Textile Wastewater for In-Plant Reuse
}

\author{
Arlindo Caniço Gomes ${ }^{1}$, Isolina Cabral Gonçalves ${ }^{1}$, Maria Norberta de Pinho², \\ John Jefferson Porter ${ }^{3 *}$
}

\begin{abstract}
The filtration characteristics of simulated dyeing effluents containing Acid Orange 7, sodium sulfate, and a $\mathrm{pH}$ buffer made of acetic acid and sodium acetate is described using a commercially available nanofiltration membrane. The original membrane filtration properties were characterized with deionized water to provide a baseline of membrane performance. At high volumetric concentration of the test solutions, greater than $98 \%$ rejection of dye and sodium sulfate were obtained. Rejection of buffering chemicals was approximately $50 \%$ in all experiments, giving a permeate water not suitable for reuse in most dyeing operations. The final composite concentrate had a chemical oxygen demand (COD) value $>2000 \mathrm{mg} / \mathrm{L}$. No problems were encountered with anaerobic treatment of the concentrate obtained from the dyeing wastewater. Adjusting the sulfate concentration to give COD-to-sulfate ratios to 2.9, 5.4 , and 18.2 in the reactor feed had no significant alterations in the performance of the upflow anaerobic sludge blanket reactor. Water Environ. Res., 79 (2007).
\end{abstract}

KEYWORDS: nanofiltration, upflow anaerobic sludge blanket, decoloration, azo dye, sulfide.

doi: $10.2175 / 106143007 \mathrm{X} 156844$

\section{Introduction}

The prevailing sources of color in most textile wastewaters are azo dyes (Plumb et al., 2001; Schoeberl et al., 2004). The present work intends to demonstrate the environmental and economical benefits arising from jointly using membrane technology, namely nanofiltration (NF), and the upflow anaerobic sludge blanket (UASB) reactor for the elimination of textile pollutants concentrated in the retentate and fresh water saving through recycling of the membrane permeate. The nanofiltration filtration experiments were performed with solutions containing chemicals used in dyeing processes-the azo dye Acid Orange 7 , sodium sulfate $\left(\mathrm{Na}_{2} \mathrm{SO}_{4}\right)$, and a $\mathrm{pH}$ buffer system made with a mixture of acetic acid and sodium acetate, prepared according to the recommended formulations for wool dyeing baths. The effects of sulfate ions $\left(\mathrm{SO}_{4}{ }^{-2}\right)$ on the removal of color and chemical oxygen demand (COD) were documented by varying the concentration of sulfate in the feed solution entering the UASB reactor.

Many of the ionic dyes, which are applied to textile fibers, contain the azo group $\left(\mathrm{R}_{1}-\mathrm{N}=\mathrm{N}-\mathrm{R}_{2}\right)$, which contributes to the color.

\footnotetext{
${ }^{1}$ Department of Chemistry, University of Beira Interior, Covilhã, Portugal.

${ }^{2}$ Department of Chemical Engineering, Instituto Superior Técnico, Lisboa, Portugal.

3* School of Materials Science and Engineering, Clemson University, Clemson, South Carolina 29634; e-mail: porter@clemson.edu.
}

Generally, this azo group is also responsible for the recalcitrant nature of the dye molecules in the aerobic process and allows the dye to accumulate in the sludge generated (bioaccumulation) (Krul and Döpkens, 2004; Vandevivere et al., 1998).

Several alternative technologies to the aerobic processes have been proposed, such as pre-, post- or main treatment processes for dye and salt removal, and have been evaluated in both laboratory and full-scale conditions. The following two important conclusions can be derived from a review of the literature:

(1) The need for membrane processes for achieving salt, color, and COD removals; and

(2) The reduction in effluent volume, which is obtained when treated wastewater is recycled.

In most cases, membrane technologies provide the quality of water, which is suitable for use in the dyeing process. An example of the success of the application of membrane technologies to textile wastewater is illustrated in Table 1, where wastewaters from six different textile plants were treated with a pilot-scale reverse osmosis pilot system over a period of 1 month. The results show that $90 \%$ of the wastewater volume could be recovered as highquality permeate water suitable for reuse in the plant. The resulting concentrate water could be treated by conventional aerobic biological treatment to give $84 \%$ 5-day biochemical oxygen demand $\left(\mathrm{BOD}_{5}\right)$ and $57 \%$ COD removal, respectively.

In the special case of effluents from wool dyeing, typical COD values ranging from 300 to $3000 \mathrm{mg} / \mathrm{L}$ have been observed (European IPPC Bureau, 2002). To concentrate these waste streams, by membrane technologies, and apply anaerobic treatment to the concentrate would provide an interesting challenge as an alternative technology for their treatment. This would represent a decrease in the volume of the industrial effluent being treated and allow less volumetric loading on the anaerobic process. Furthermore, concentrate from the filtration process can sometimes be directly reused, for example, the recovery of indigo dye and polyvinyl alcohol sizing chemicals (Porter, 1996). This would reduce the volume and amount of chemicals to be treated.

Membrane Technology. Nanofiltration is a pressure-driven membrane process that produces treated water with a purity that lies between that obtained with reverse osmosis and ultrafiltration. Nanofiltration technology generally has the advantages of operation at lower pressure than reverse osmosis and higher fluxes than reverse osmosis. Compared with ultrafiltration, nanofiltration has a higher retention of salts and organic molecules than ultrafiltration 
Table 1-Biological aerobic treatment of the concentrate residue obtained from reverse osmosis treatment of the composite wastewater from six textile finishing plants recovering $\mathbf{9 0} \%$ permeate water for plant reuse (Porter and Sargent, 1977).

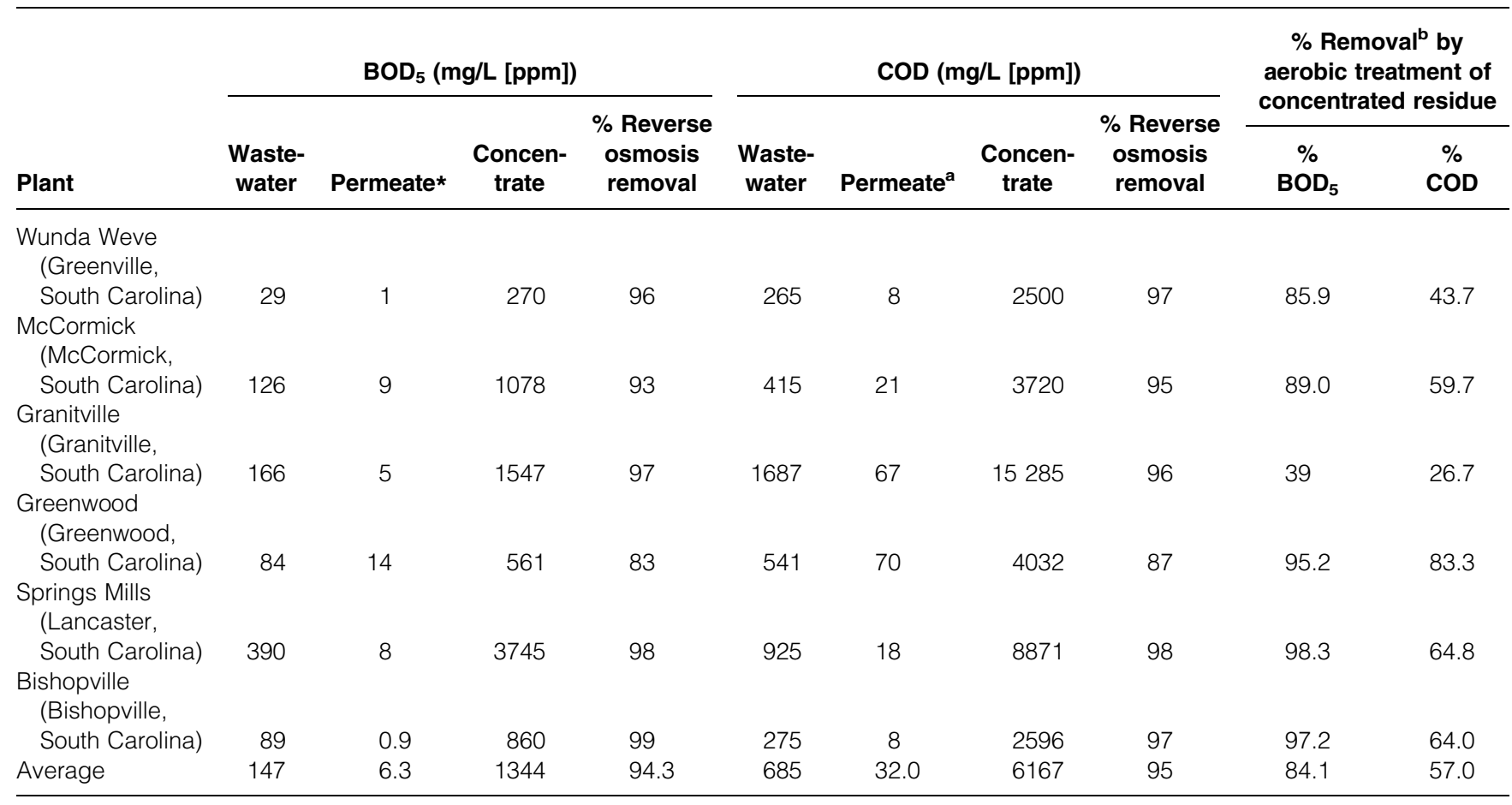

a The color removal for these samples ranged from 89 to $100 \%$ and was suitable for reuse in plant processes.

$\mathrm{b}$ This represents the percent removal by aerobic treatment using a 10-day retention, return sludge laboratory unit.

(including molecular weights above $200 \mathrm{~g} / \mathrm{mol}$ ), while giving lower filtration rates per unit area than ultrafiltration (Mulder, 1996).

Several researchers demonstrated the economical and technological advantages from the application of nanofiltration membranes to the treatment of textile wastewaters (Koyuncu and Topacik, 2002; Rozzi et al., 1999). The color removal achieved is high-generally above the minimum quality requirements for water recirculation proposed by Brandon and Jernigan (1981); at 97\%, the sodium chloride rejection is in between 10 and $80 \%$ and, for sodium sulfate, from 90 to $98 \%$. The retentate or concentrate produced contains most of the chemicals present in the original feed wastewater and, in many cases, can be reused in the process, reducing the quantity of production dyes or chemicals needed. However, it is often difficult to reuse the concentrated chemicals when they are unstable or have accumulated undesirable contaminants (Aurich, 1995; Vandevivere et al., 1998). The treatment of concentrated wastewater from membrane filtration may be difficult, in some cases, with the disposal of the concentrate streams considered, by some authors, to be a major drawback for the implementation of membrane technology (Krull and Döpkens, 2004; Schoeberl et al., 2004). The successful application of anaerobic treatment for removal of color from textile dye wastewaters, particularly for azo dyes, is related to the azo bond cleavage by reduction for oxidation-reduction potential under $-220 \mathrm{mV}$.

Anaerobic Treatment. The UASB reactor is currently the most widely used in Western Europe, being applied to the treatment of wastewaters of medium to high organic loading rate (OLR), such as wastewater from the food/beverage, chemical, petrochemical, pulp/ paper, and other industries, which is known to contain toxic and recalcitrant compounds (van Lier et al., 2001).
Anaerobic treatment of effluents with high concentrations of sulfate/sulfide, such as those generated by many industrial processes, such as pharmaceutical, tannery, pulp and paper, petrochemical, and textile wastewater, was considered difficult to control and treat, because methane-producing bacteria (MPB) and sulfatereducing bacteria (SRB) will compete for the use of hydrogen and acetate. The outcome of the competition between SBR and MPB is not always clear, because it depends on the composition of many components in complex waste streams (Maillacheruvu and Parkin, 1996; McCartney and Olesziewicz, 1993). However, van Lier et al. (2001) reported high sulfate and COD removals in anaerobic reactors treating sulfate-rich wastewaters, even for specific waste streams containing no or very little organic matter. Examples of such effluents are those from mining, mineral processing, metallurgical, and chemical industries; under these conditions, it is necessary to supply an appropriate electron donor and carbon source to the wastewater.

\section{Methodology}

Nanofiltration Experiments. The research reported here was carried out with a commercial pilot-scale nanofiltration unit (LabUnit M20, Danish Separation Systems AS, Denmark) using 0.072 $\mathrm{m}^{2}$ of NF45 flat-sheet membrane (Filmtec, Midland, Michigan). The nanofiltration experiments were performed at $25{ }^{\circ} \mathrm{C}$, with transmembrane pressures from 10 to 35 bar (for permeation tests at constant concentration) or 16 bar (for concentration tests) at the maximum circulation velocity allowed by the recirculation pump $(0.87 \mathrm{~m} / \mathrm{s})$. The experiments with simulated dye effluent (see Table 2 for solutions composition) were conducted in a concentration mode 
Table 2-Composition of simulated dyeing wastewater used for concentration experiments.

\begin{tabular}{llc}
\hline Run & \multicolumn{1}{c}{ Solute } & Amount $\mathbf{( g / L )}$ \\
\hline \multirow{2}{*}{1} & $\mathrm{Na}_{2} \mathrm{SO}_{4}$ & 0.6 \\
& $\mathrm{C}$. I. Acid orange 7 & 0.1 \\
& $\mathrm{Na}_{2} \mathrm{SO}_{4}$ & 0.6 \\
2 & C.I. Acid orange 7 & 0.1 \\
& Sodium acetate & 2.4 \\
& Acetic acid & 0.9 \\
\hline
\end{tabular}

with permeate collection (the maximum concentration factor achieved was 3.0, which represents approximately $70 \%$ of the water recovery ratio). Basic procedures during the tests and for the membrane cleaning operation were carefully performed to recover the flux reduced by interactions of solutes with the membrane and were the same as those previously reported (Gomes et al., 2005). Membrane performance was basically measured in terms of permeate flux, $J_{v}$, (kilograms per square meter per hour) and coefficient of rejection, $f$, for the conductivity (salt), absorbance (dye), and COD (for the buffer components). Pure water with conductivity less than $1 \mu \mathrm{S} / \mathrm{cm}$ was used for solution preparation and membrane cleaning. All chemicals used for experiments were reagent-grade and were used without further purification. The dye used (C.I. acid orange 7 , Figure 1) was chosen because of its low molecular weight (MW $=351 \mathrm{~g} / \mathrm{mol}$ ), which is close to the values of molecular weight cutoff (MWCO) for nanofiltration membranes (Mulder, 1996).

Upflow Anaerobic Sludge Blanket Experiments. The UASB reactor, shown in Figure 2, consisted of two polyvinyl chloride columns, connected at the base and top to form an inner and external chamber, with 7.5 and $12 \mathrm{~cm}$ of internal and external diameter, respectively. The working reactor volume (inner chamber) was of $1160 \mathrm{~mL}$, and the external chamber was used for hot water circulation to ensure an operational temperature of $37 \pm 2{ }^{\circ} \mathrm{C}$ (mesophilic range). The reactor was equipped with several sample ports. In the reactor top, a gas-liquid-solid separation device, connected to a liquid displacement type system, was used to measure and collect the produced biogas for analysis. The UASB was operated with a hydraulic retention time (HRT) of approximately 7 hours and an average organic load of $7.5 \mathrm{~kg} \mathrm{COD} / \mathrm{m}^{3} / \mathrm{d}$ and seeded with sludge from a full-scale UASB plant treating an industrial pulp and paper effluent.

The reactor feed composition was similar to that used by Wiegant and Lettinga (1985), with an average COD of $2215 \pm 380 \mathrm{mg} / \mathrm{L}$. Glucose $(2.13 \mathrm{~g} / \mathrm{L})$ was used as the organic source of carbon and energy, because it is readily degraded and produces a wide range of anaerobic bacteria and forms a biomass that has good settling prop-

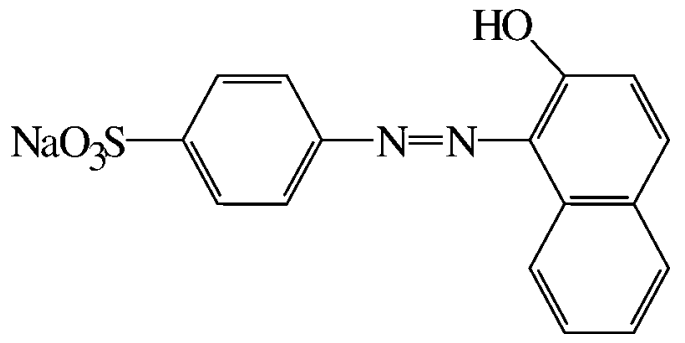

Figure 1-Chemical structure of C.I. acid orange 7 (MW = $350.3 \mathrm{~g} / \mathrm{mol}$ ).

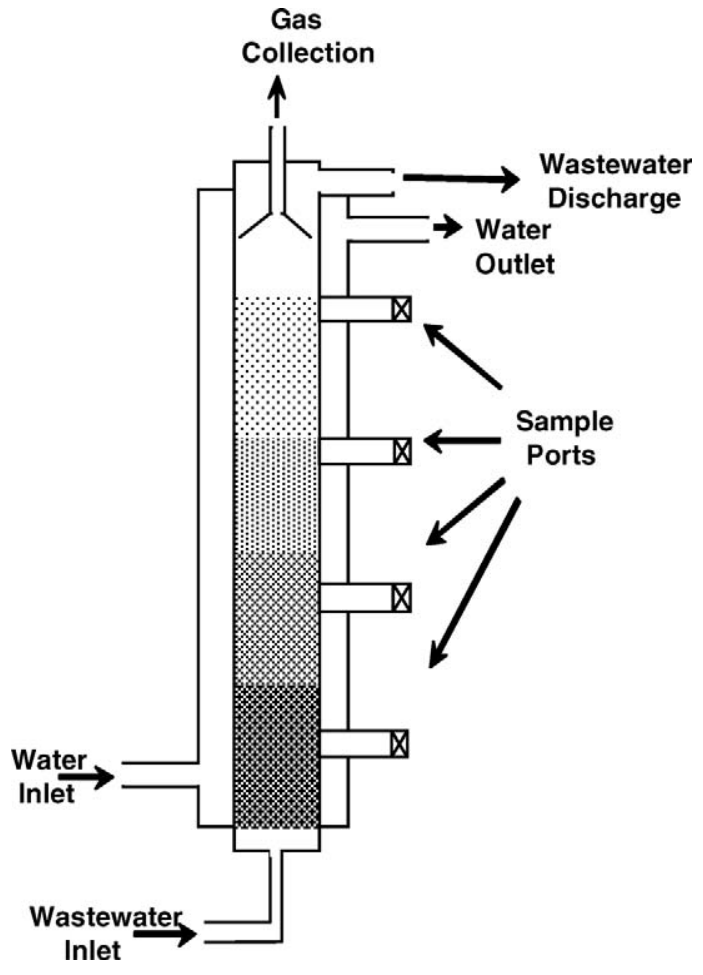

Figure 2-Laboratory anaerobic treatment reactor (UASB type).

erties. It also favors the incubation of several anaerobic bacteria, such as SRB, which are needed for sulfate metabolism. In this context, anaerobic essays were perform with a model solution prepared with glucose (complex substrate), because acetate is an intermediate produced during the acid (fermentative) step of the anaerobic metabolism.

The reactor was operated over four different time periods referred to as "phases". The startup period was called phase 1, lasted for 370 days, and had no sulfate or dye present in the feed solution. In the following three phases, dye concentration in the feed solution was maintained at $150 \mathrm{mg} / \mathrm{L}$, and sodium sulfate concentration was increased from $130 \mathrm{mg} / \mathrm{L}$ in phase 2 to $500 \mathrm{mg} / \mathrm{L}$ in phase 3 and finally to $800 \mathrm{mg} / \mathrm{L}$ in phase 4 . The ranges of sulfate levels were those commonly present in finishing textile wastes (European IPPC Bureau, 2002). The changes to the feed solution being fed to the anaerobic reactor provided COD-to-sulfate ratios of 2.9, 5.4, and 18.2 in phases 2,3 , and 4 , respectively.

Analytical Techniques. In the nanofiltration experiment, samples of the feed solution and permeate were taken for analysis during nanofiltration trials in the recirculation mode and from permeate and concentrate streams during concentration studies. The volumetric flowrate for permeate was measured when samples were taken for analysis over the course of the nanofiltration experiment.

The $\mathrm{pH}$, conductivity, and COD analysis were performed according to Standard Methods (APHA et al., 1992). The sulfate concentration was determined by high-performance liquid chromatography. Suspended solids, volatile suspended solids (VSS), and COD values for filtered samples (soluble COD) were also analyzed according to Standard Methods (APHA et al., 1992). The dye concentration was determined based on a calibration curve correlating concentration and absorbance at $482 \mathrm{~nm}$. The degradation 
Table 3-Experimental results from recirculation tests with selected solutes. ${ }^{*}$

\begin{tabular}{|c|c|c|}
\hline Solution composition & $\begin{array}{l}\text { Permeate flux } \\
\left(\mathrm{kg} /\left[\mathrm{h} \cdot \mathrm{m}^{2}\right]\right)\end{array}$ & $\begin{array}{c}\text { Solute rejection } \\
\text { coefficient }(\%)\end{array}$ \\
\hline Pure water & 59.64 & \\
\hline Sodium chloride, 2000 mg/L & 44.91 & 44.0 \\
\hline $\mathrm{NaSO}_{4}, 2000 \mathrm{mg} / \mathrm{L}$ & 45.26 & 98.4 \\
\hline Calcium chloride, 2000 mg/L & 46.74 & 60.5 \\
\hline C.I. acid orange $7,200 \mathrm{mg} / \mathrm{L}$ & 49.88 & 98.6 \\
\hline C.I. acid orange $7,2000 \mathrm{mg} / \mathrm{L}$ & 47.71 & 99.8 \\
\hline $\begin{array}{l}\text { Sodium acetate, } 2400 \mathrm{mg} / \mathrm{L} \\
\text { Acetic acid, } 900 \mathrm{mg} / \mathrm{L}\end{array}$ & 58.75 & 50.6 \\
\hline
\end{tabular}

*Experimental conditions: pressure $=16$ bar, crossflow $=0.87 \mathrm{~m} / \mathrm{s}$ and temperature $=25^{\circ} \mathrm{C}$.

of the dye structure was analyzed by running UV-visible spectra (Lambda 6 spectrophotometer, Perkin Elmer, Wellesley, Massachusetts). All samples were analyzed within 2 hours after being collected, to avoid interferences caused by light and oxygen. Samples were previously filtered with $1.2-\mu \mathrm{m}$-porosity glass microfiber filters. The analyses for determination of the percentage of methane $\left(\mathrm{CH}_{4}\right)$ in the biogas produced under different conditions were performed by gas chromatography, as previously reported (Brás, 2004).

\section{Results and Discussion}

Membrane Characterization. Before using the membrane in actual experiments, it was pressurized to 42 bar for 3 hours, with recirculation of pure water, to avoid pressure effects on the membrane structure in subsequent experiments. The membrane characterization was obtained by the determination of membrane pure water permeability, MWCO, and by permeation experiments with selected solutes, as reported in Table 3 and described previously (Gomes et al., 2005). The initial pure water permeability value, $3.7 \mathrm{~kg} /\left(\mathrm{m}^{2} \cdot \mathrm{h} \cdot\right.$ bar $)$ was used as a reference during the membrane cleaning.

The rejection order for the salts shown in Table 3 follows the order of their diffusion coefficients in water, showing that membrane superficial charge was small or dependent on the adsorption of co-ions and not in agreement with the Donnan Exclusion Principle (Peerters et al., 1998).

The rejection of Orange 7 is compatible with the MWCO of the membrane $(320 \mathrm{~g} / \mathrm{mol}$ considering $97 \%$ rejection) and increases with increasing concentration. If dye concentrations near the membrane surface were high, it would be possible for dye to aggregate at the membrane surface and enhancing dye removal. However, as the maximum concentration of dye used was equal to or below
$100 \mathrm{mg} / \mathrm{L}(100 \mathrm{ppm})$, it is not believed to be significant. As reported in a previous study (Gomes et al., 2005), the membrane permeation performance is affected by dye adsorption, which can contribute to a decay of flux higher than that expected. The dye colored the membrane during the experiments and could not be removed by normal cleaning procedures recommended for the membrane. The consequences of dye adsorption did not influence membrane rejection at sodium chloride concentrations of $2 \mathrm{~g} / \mathrm{L}$ concentration, which was in agreement with the reference values presented by the manufacturer. The filtration rate with pure water did decrease in the experiments, to only $5 \%$ of its initial value, as previously observed (Gomes et al., 2005). The lower rejection of the acetate buffer components is reasonable, taking into consideration that the molecular weight of acetic acid $(60 \mathrm{~g} / \mathrm{mol})$ is substantially below the MWCO of the membrane.

Membrane Concentration Runs. The results obtained with concentration experiments are reported in Table 4 and indicate no significant differences in rejection properties of the membrane filtering sodium sulfate and $\mathrm{AO} 7$ alone (run 1) and in the presence of acetate buffer (run 2). It was important to establish the maximum amount of permeate water that could be recovered by membrane filtration, keeping in mind that the high quality demands for process water that is required for the dyeing process. In addition, the concentrate stream must be compatible with the wastewater treatment process currently used by the textile plant or one that may be installed for its treatment.

The absence of any color is the most important requisite for process water in the textile industry. However, other impurities in the permeate water may affect the dye's adsorption and the resulting color of the dyed goods. The apparent rejection coefficient, $f$, which depends on the measured concentration of solute, was calculated according to the following relationship:

$$
f=\frac{c_{f}-c_{p}}{c_{f}}
$$

Where

$$
\begin{aligned}
c_{f} & =\text { solute concentration in feed solution }(\mathrm{mg} / \mathrm{L}), \text { and } \\
c_{p} & =\text { solute concentration in the permeate water }(\mathrm{mg} / \mathrm{L}) .
\end{aligned}
$$

In Figure 3, the flux and rejection coefficients are shown, with the corresponding concentration values obtained for both runs. As expected, flux decrease is a consequence of increasing solute concentration shown for run 1 , which gave a linear increase with a small decay of $2 \%$ near the end of the experiment. However, during run 2 , the flux reduction occurs at $17 \%$ concentration of the treated wastewater. At volumetric concentration factor (VCF, defined as the ratio between the initial volume present in the feed tank, $V_{i}$, and $V_{c}$, the volume of concentrate, which is the difference of $V_{i}$ minus the volume of collected permeate) factors above 2 , the decay is very obvious and is followed by a reduction in the rejection coefficient for

\begin{tabular}{|c|c|c|c|c|c|c|c|c|c|c|c|c|}
\hline Test & \multicolumn{4}{|c|}{ Initial solution } & \multicolumn{4}{|c|}{ Produced permeate } & \multicolumn{4}{|c|}{ Produced retentate } \\
\hline 1 & 3.45 & 597 & 77 & Not available & 3.51 & 42 & 2.1 & Not available & 3.47 & 1707 & 229 & Not available \\
\hline 2 & 5.00 & 602 & 84 & 2903 & 4.88 & 59 & 3.9 & 2578 & 5.27 & 1721 & 236 & 3579 \\
\hline
\end{tabular}

Table 4-Characteristics of the initial solutions used in concentration tests and of the produced permeated and concentrate streams (VFC $=3$ ). 
a)

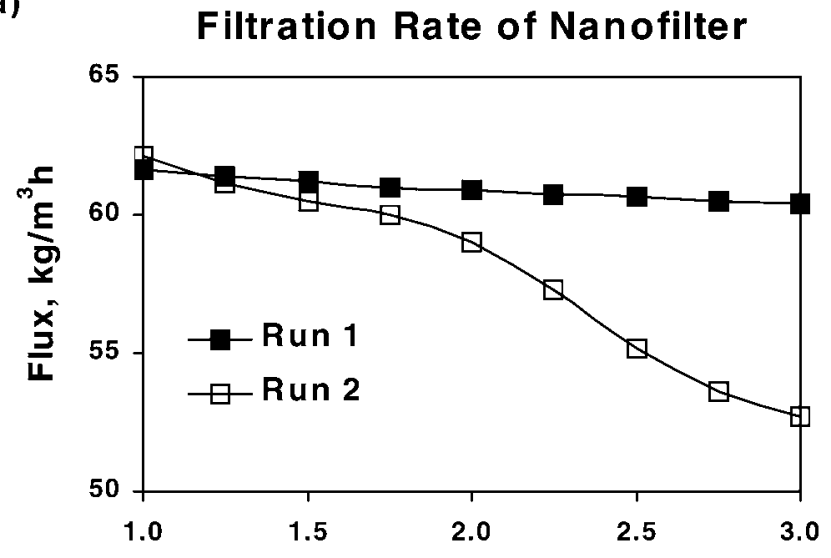

Concentration Factor

b)

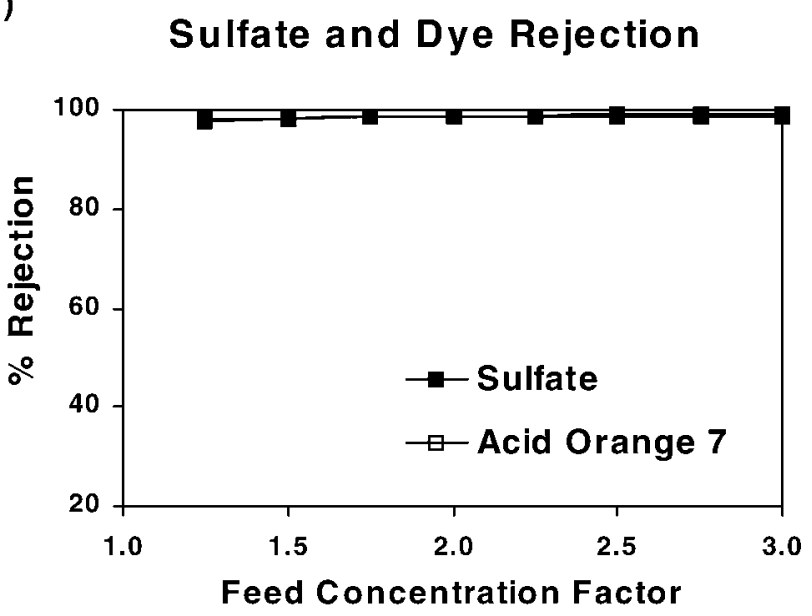

c)

\section{Sulfate, Dye \& COD Rejection}

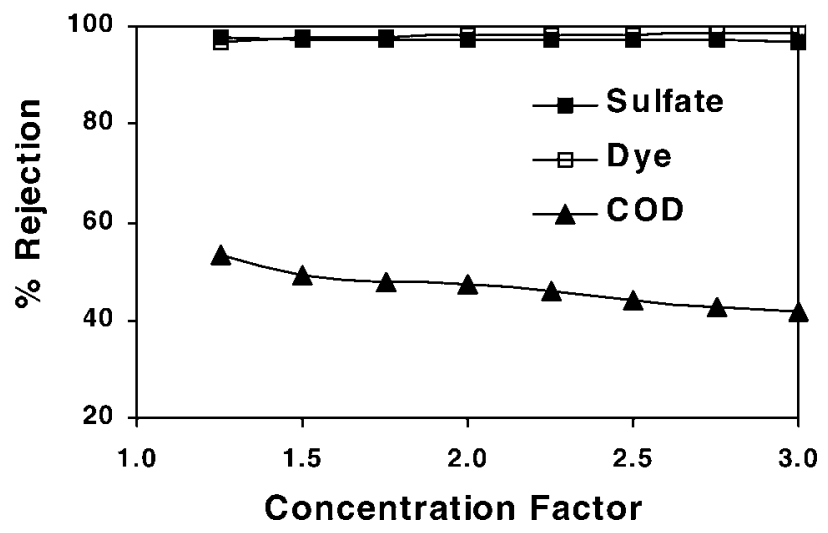

Figure 3-Membrane performance for the polyamide nanofilter: (a) filtration rate, (b) solute rejection run 1, and (c) solute rejection run 2.

COD. This is mainly attributed to the buffer components (acetate and acetic acid) that were not rejected as well by the membrane as other components in the simulated wastewater. The lower rejection of the acetic acid can be attributed to the chemical composition of the NF45 membrane- a polymeric aromatic piperazine amide. Organic amide would be expected to have a high affinity for molecules like acetic acid and tend to adsorb the acetic acid onto the membrane surface. As a result, a reduction of the rejection of acetic acid would be observed, because, at the membrane surface, a much higher concentration of acetic acid than for other solutes, for which the membrane had little or no affinity, would occur. Such a concept is supported by the data shown in Table 1, where textile wastewaters from six textile plants, known to use acetic acid in their processes, showed an average of $95 \%$ rejection of all organics in the wastewater.

Notice that, in run 2, it was possible to evaluate the removal of buffer components by subtracting the COD contributed by the dye from the total COD, using a relationship developed by Brás (2004) (i.e., $2.3 \mathrm{mg} \mathrm{COD} / \mathrm{mg} \mathrm{AO7)}$. The $\mathrm{pH}$ values of both solutions shown in Table 4 should cause the membrane to have a positive charge ( $\mathrm{pH}$ solution values under 6.5). In this case, $\mathrm{Xu}$ and Lebrun (1999) found that the solute concentration had a smaller effect on the rejection coefficient than when the membrane was negatively charged, although it is similar to results obtained when the membrane is neutral ( $\mathrm{pH}$ solution of 6.5). The membrane rejection for the dye was constant and above 99\% for dye and $97 \%$ for salt during run 1 and independent of VCF increase. In run 2, the rejection of dye and sodium sulfate was above $90 \%$ even though the COD rejection was only $12 \%$. The small rejection of membrane for the buffer chemicals (measured by COD) and the decrease of flux between runs 1 and 2 may be related to the adsorption of acetic acid to membrane polymer and to the extra osmotic pressure caused by the increasing electrolyte concentration of 23\% shown in Table 4 .

As noted earlier, all attempts to remove the adsorbed $\mathrm{AO} 7$ from the membrane were unsuccessful. In previous work, a decrease in flux with increasing dye concentration was observed (Gomes et al., 2005) when the dye concentration was between 2 and $2000 \mathrm{mg} / \mathrm{L}$. The present work used $\mathrm{AO} 7$ at concentrations below $84 \mathrm{mg} / \mathrm{L}$ and would have a smaller effect on the flux. The increase in solute concentration will cause a corresponding increase in concentration polarization that can occur during the run and is a result of the buildup of charged ions at the membrane surface. In this case, Reynolds number values below 1000 were calculated from the experimental data and are representative of laminar flow (Madsen, 1989). This buildup of ions at the membrane surface would tend to reduce electrostatic interactions between the charged solute ions and the charged membrane surface.

The samples of permeate and concentrate collected at the maximum VCF achieved (70\% water recovery) were analyzed for reuse and UASB treatment, respectively. The data presented in Table 4, particularly the COD values for the permeate water produced in run $2(2578 \mathrm{mg} / \mathrm{L})$, indicate a small chance for water reuse. The COD-to-sulfate ratio of the concentrate stream produced, run 2, is 2.1 and is near the minimum value of 2.9 tested for UASB experiments (Table 5). The minimum value recommended for UASB evaluation is lower than 1 (Choi and Rim, 1991), which is much lower than those values obtained in this work.

Upflow Anaerobic Sludge Blanket. The bioreactor performance was evaluated by measuring COD, sulfate, and dye removal and analyzing the methane content of the collected biogas. These parameters were monitored as the sulfate concentration of the feed solution was increased. The $\mathrm{pH}$ of the influent was maintained between 6.5 and 7.5, and the feed flow was adjusted to give a retention time of 7 hours (ranging from 6 hours and 20 minutes to 7 hours and 30 minutes) in the reactor. The COD in feed solutions varied between 2215 and $2712 \mathrm{mg} / \mathrm{L}$. As the real textile effluents 
Table 5-Average UASB reactor performance.

\begin{tabular}{|c|c|c|c|c|c|c|c|c|c|c|c|c|}
\hline Reactor performance & \multicolumn{3}{|c|}{ Phase 1} & \multicolumn{3}{|c|}{ Phase $2^{a}$} & \multicolumn{3}{|c|}{ Phase $3^{a}$} & \multicolumn{3}{|c|}{ Phase $4^{a}$} \\
\hline COD removal (\%) & 29 & 88 & 7 & 6 & 83 & 2 & 22 & 84 & 5 & 10 & 82 & 4 \\
\hline $\mathrm{SO}_{4}^{-2}$ & & & & 2 & 79 & 8 & 2 & 75 & 3 & 3 & 62 & 5 \\
\hline Decolorization (\%) & & & & 3 & 88 & 4 & 11 & 94 & 5 & 5 & 85 & 7 \\
\hline
\end{tabular}

${ }^{\text {a }}$ Acid orange $7=150 \mathrm{mg} / \mathrm{L}$.

${ }^{\mathrm{b}} \mathrm{N}=$ number of samples; $\mathrm{SD}=$ standard deviation.

are complex, containing many molecules of different sizes, the retentate from nanofiltration experiments and those that may be produced by ultrafiltration or even microfiltration should be sent to the UASB reactor. The evaluation of the reactor performance, in the presence of more complex substrates, will provide useful information to understand the effectiveness of the UASB reactor as a treatment method for real textile effluent.

Reactor Startup and Steady-State Operation. The initial operating period of approximately 1 year was used to ensure the preferential development of methanogenic bacteria created in the absence of dye and sulfate (phase 1). The COD profile and the reactor performance shown in Figures 4 and 5 are typical for this reactor configuration. The biomass profile (VSS) is related to the COD removals achieved as the feed solution flows up the vertically configured reactor shown in Figure 2.
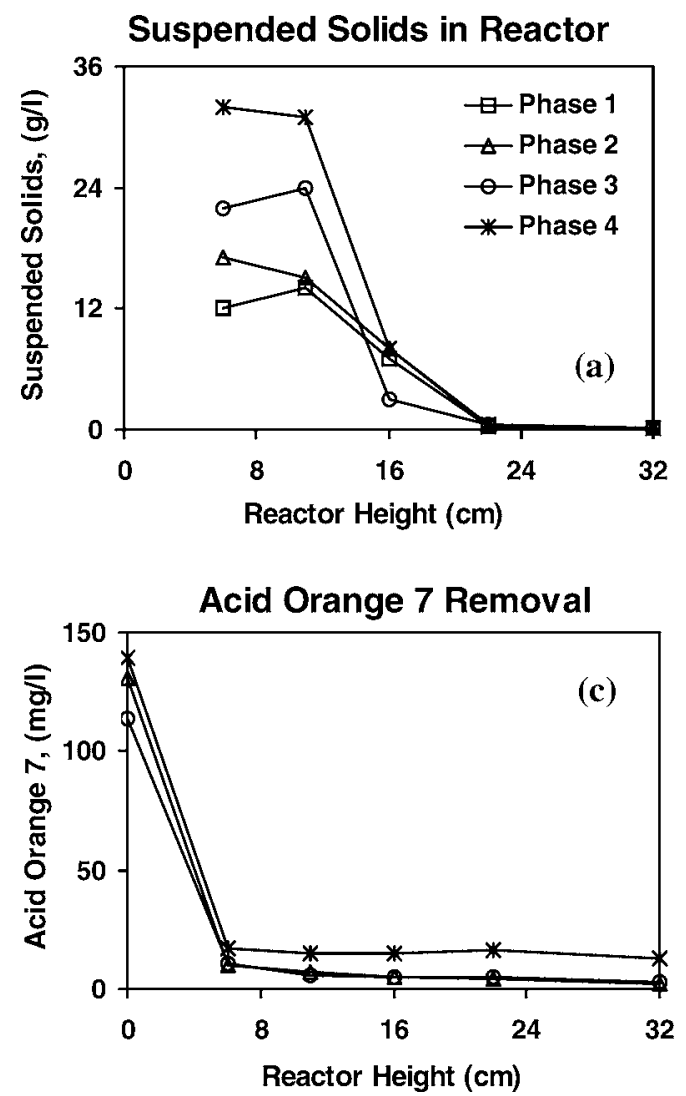

Effect of the Addition of Dye and Sulfate Concentration to the Feed Solution. The next operational conditions were to introduce azo dye (constant concentration of $150 \mathrm{mg} / \mathrm{L}$ ) and sulfate (130, 500 , and $800 \mathrm{mg} / \mathrm{L}$ ) to the reactor feed solution. The concentration of sulfate was progressively increased, while maintaining the dye concentration in the feed solution at its original value. In previous studies performed in this laboratory by Brás (2004), the reactor was operated at the same HRT using the same glucose feed solution used in phase 1, supplemented with $150 \mathrm{mg} / \mathrm{L} \mathrm{AO7} \mathrm{dye} \mathrm{and} \mathrm{in} \mathrm{the}$ absence of sulfate. These results indicated a good performance, with COD removals of $80 \pm 3 \%$ and color removals of $87 \pm 1 \%$.

The average influent $\mathrm{pH}$ varied from 7.6 to 8.4 , while the effluent $\mathrm{pH}$ ranged between 7.3 and 7.7, respectively, for phases 1 and 4 . The slight $\mathrm{pH}$ variation in the feed solution was considered acceptable and remained between 7.0 and 8.5 , which is in the range
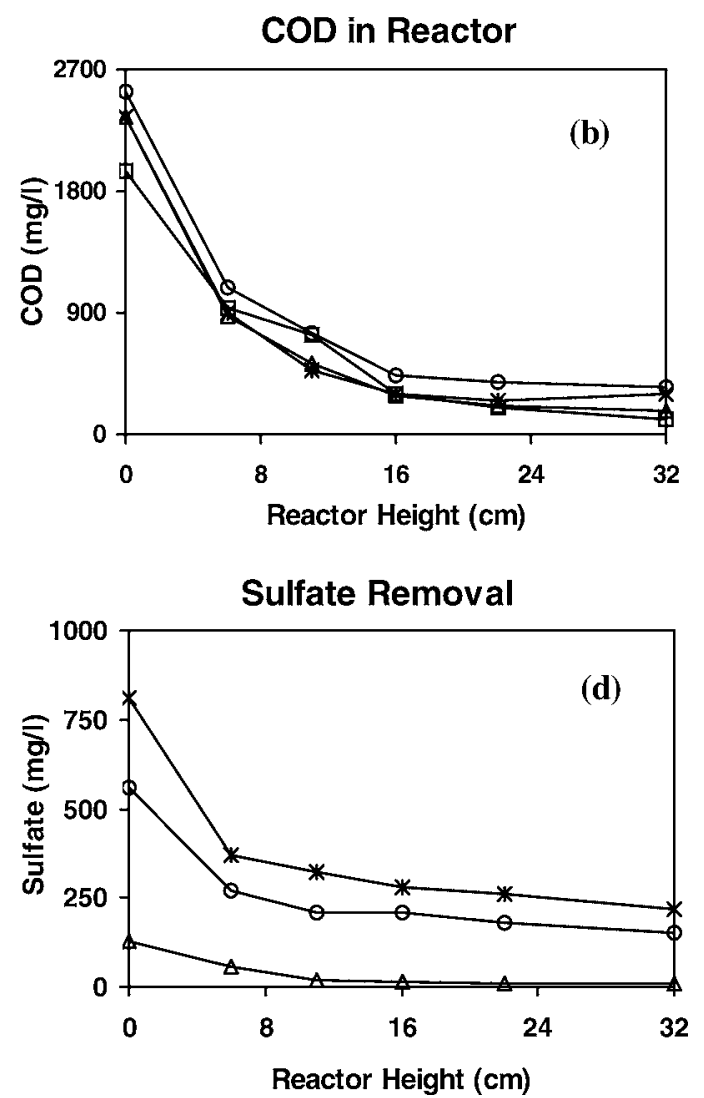

Figure 4-Results from determinations made with samples taken at different levels of reactor height. 

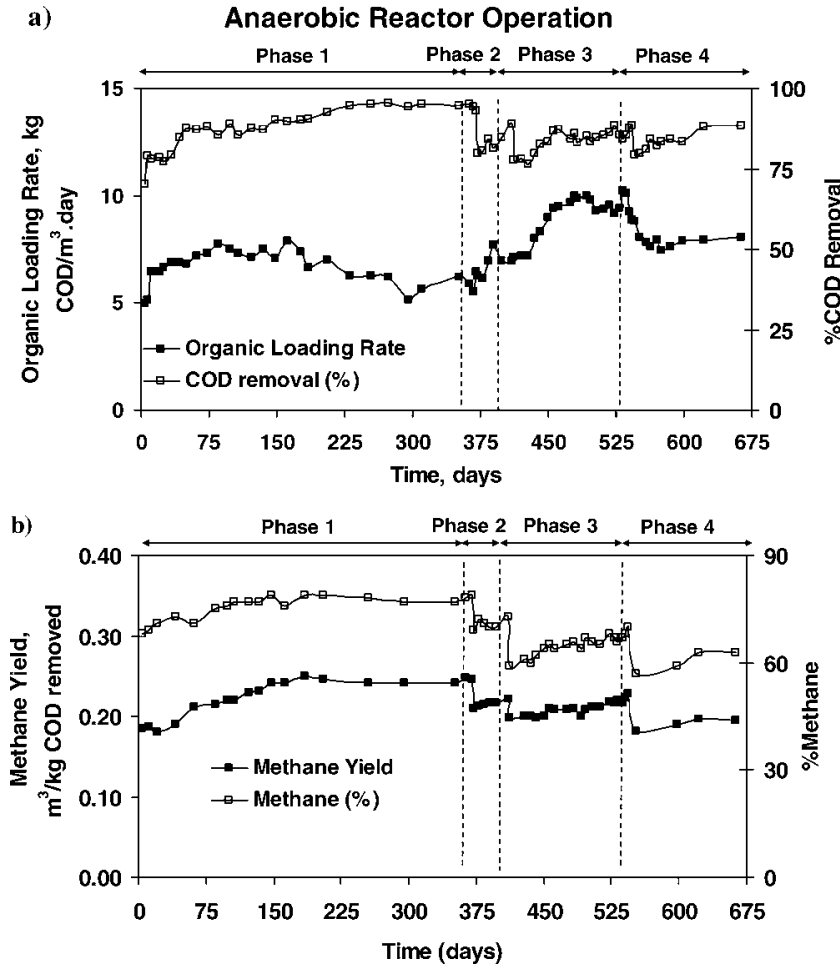

Figure 5-(a) Time course of COD removal and OLR (kg COD $/ \mathrm{m}^{3} \cdot$ day); (b) methane yield $\left(\mathrm{m}^{3} /[\mathrm{kg}\right.$ COD removed]) percentage of methane in collected biogas.

required for the metabolism of strict anaerobes, such as methanogenic bacteria, that are more susceptible to inhibition factors. No significant influence of sulfide inhibition is expected to occur at this $\mathrm{pH}$ range, as the toxic non-ionized form of sulfide is at a very low concentration. Several studies with anaerobic reactors have been carried out in similar conditions and showed that inhibition depends not only the range of $\mathrm{pH}$, but also on the COD-to-sulfate ratio (Choi and Rim, 1991). The time (days) versus COD removal and OLR experienced during each operational phase are presented in Figure 5. The time (days) versus methane yield, expressed in cubic meters methane per kilogram COD removed, and the percentage of methane in the collect biogas are also graphically represented.

The average values for the COD removal indicated in Table 5 are affected slightly by the increasing the sulfate concentration in the feed going from phase 2 to phase 4 and by the presence of dye in the feed solution after phase 2 . The COD removal varied from 88 and $82 \%$ going from phase 1 to phase 4 . However, organic utilization and the analyzed ratios of COD-to-sulfate proved that high sulfide levels were not present in the reactor, which would have produced significant toxic effects for both SRB and MPB microbes. These values were not corrected for the contribution of biogenic sulfide production. If the contribution of sulfide to the COD is taken into account, the COD removal increased from $95 \%$ (in phase 2), to $96 \%$ (in phase 3), and finally to $99 \%$ (in phase 4). These calculations were based on the difference in sulfate concentration in the influent and effluent streams of the UASB reactor and also were used to calculate the percentages of sulfate removal presented in Table 5. The effective concentration of sulfide inside the reactor should be less than $34 \mathrm{mg} / \mathrm{L}$ in phase $2,125 \mathrm{mg} / \mathrm{L}$ in phase 3 , and $217 \mathrm{mg} / \mathrm{L}$ in phase 4 , which would explain the high biogas flowrates obtained-
2.70 L/d (in phase 2), $3.19 \mathrm{~L} / \mathrm{d}$ (in phase 3), and $2.59 \mathrm{~L} / \mathrm{d}$ (in phase 4). These values indicate that some of the hydrogen sulfide produced was stripped from the biogas stream and that good mixing occurred in the reactor. The value of the sulfide concentration that causes the inhibition of SRB and MPB will depend on the OLR, type of substrate used, and nature of the suspended or granular sludge produced (McCartney and Olesziewicz, 1993). The influence of each of these factors will depend on the concentration of the sulfide ion in the system, which is influenced by the $\mathrm{pH}$ or dissociation of sulfide, equilibrium between the gaseous and aqueous hydrogen sulfide, and solubility of various metal sulfides.

Several authors have pointed out that is more important to look at the competition between MPB and SRB and their potential inhibition, in terms of the ratios of substrate-to-sulfate, rather than other factors. It was proven that SRB has the potential to win over MPB in the competition for the available substrates in natural environments. However, much of the research on bioreactors showed that MPB could coexist with SRB when the substrate concentration is acetate and present in a high concentration (Bhattacharya et al., 1996). The outcome of the competition for acetate during the treatment of sulfate-rich (containing) wastewaters also depends on the lower affinity of SRB for acetate than for others substrates (Colleran and Pender, 2002). At COD-to-sulfate ratios of 1.7 to 2.7, MPB and SRB were observed to be in competition for the available substrate. Bellow this range, SRB was dominant, while, at higher ratios, MPB was dominant (Choi and Rim, 1991). The tested COD-to-sulfate ratios of 2.9, 5.4, and 18.2 were favorable for maintenance of the equilibrium between organic removal and sulfate reduction, which was in agreement with the present work.

The COD, VSS, sulfate, and dye concentration profiles are presented in Figure 4. The COD consumption along with color and sulfate removal occurred at the bottom section of the reactor, essentially before the influent reached the third sample port $16 \mathrm{~cm}$ from the bottom of the reactor. The overall performance of the reactor is presented in Table 5. The mean overall percentage of decoloration achieved for samples collected at the first simple port (situated at $6 \mathrm{~cm}$ height) was $88 \%$ (in phase 2), 94\% (in phase 3), and $85 \%$ (in phase 4 ). These results are the consequence of the limited dye concentration used and the decoloration rate being faster than organic substrate utilization and sulfate reduction, which was confirmed by the COD, sulfate, and dye concentration profiles presented in Figure 4. It is important to report that decoloration of the dye was not influenced by increases in sulfate concentration. However, sulfide, which was present in this system, is well-known as an electron source for the reduction of azo bonds in a process designated as abiotic reduction. Some authors have reported the possibility of the sources of this electron being used in addition to the flow of the electron flow produced by substrate metabolism (Méndez-Paz et al., 2003). The analysis of the spectra of filtered samples taken from the influent and effluent show that the same profile variation previously reported was related to the cleavage of the azo bond (Gonçalves et al., 2000).

The biomass concentration profiles in Figure 4 show no interference in biomass formation caused by dye or sulfate concentrations and actually increased from phase 1 to phase 4 . The measured concentration of biomass for phase 4 (35 g VSS/L) was higher than that obtained in phase 1 (13 g VSS/L), for samples taken at a $6-\mathrm{cm}$-high port (Figure $4 \mathrm{a}$ ). This may be attributed to the development of different consortia of anaerobic bacteria because of the presence of SRB and the higher organic loads fed to the reactor in phases 3 and 4 . 


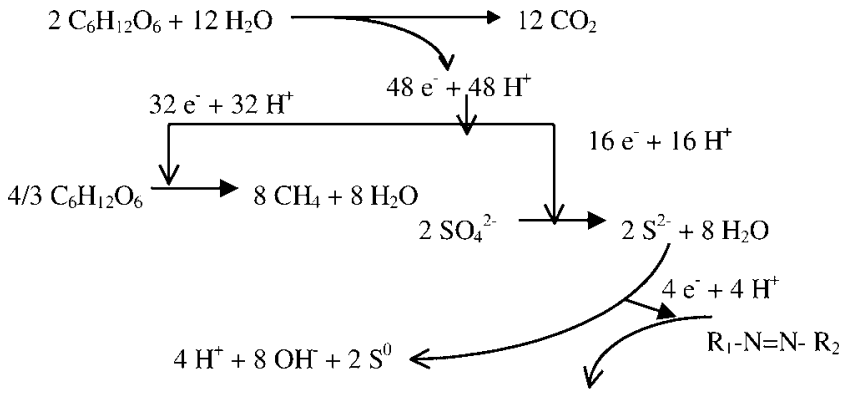

$$
\mathrm{R}_{1}-\mathrm{NH}_{2}+\mathrm{R}_{2}-\mathrm{NH}_{2}
$$

Figure 6-Representation of the possible metabolic pathways for production of methane, reduction of sulfate and azo dye bond.

Increases in the concentration of sulfate caused a reduction in the percentage of methane in the collected biogas, that is, from $76 \%$ in phase 1 to $61 \%$ in phase 4 . This observation is valid, even though the amount of inorganic carbon dioxide introduced by the use of sodium bicarbonate to control the $\mathrm{pH}$ varied between operational phases. The $\mathrm{pH}$ was 7.6 and 8.4 in phases 1 and 4, respectively. The amount of biogas collected each day was approximately constant, having an average value of $2.5 \mathrm{~L} / \mathrm{d}$. However, the methane yield decreased from $0.2248 \mathrm{~m}^{3} \mathrm{CH}_{4} / \mathrm{kg}$ COD removed to $0.1907 \mathrm{~m}^{3}$ $\mathrm{CH}_{4} / \mathrm{kg}$ COD removed, as the sulfate concentration increased from 130 to $800 \mathrm{mg} / \mathrm{L}$. This decay of $16 \%$ is essentially a result of the increase utilization of glucose by SRB and to the detriment of MPB, providing the electron flow needed for sulfate reduction (Figure 5). Also, it should be pointed out that the values shown in Figure 5 are, in general, lower than the theoretical value of $0.382 \mathrm{~L} \mathrm{CH}_{4} / \mathrm{g} \mathrm{COD}$ removed expected for glucose as a main carbon source (without considering the COD used for biosynthesis). The discrepancy found in the results could be explained by the content of the soluble fraction of methane present in liquid phase and by the low efficiency achieved in the gas-solid-liquid separation system, leading to a decrease of the collected biogas.

A simplification of the electron flow in the UASB reactor is shown in Figure 6. This diagram is a simplification of complex reactions involving the glucose consumption in the reactor, namely, for methane production, sulfate reduction and decoloration of azo dye. If we consider that $1 \mathrm{~g}$ glucose is equivalent to $1.07 \mathrm{~g} \mathrm{COD}$, after subtracting the dye and sulfide oxidation contributions, respectively, $2.3 \mathrm{~g} \mathrm{COD} / \mathrm{g}$ dye and $1.06 \mathrm{~g} \mathrm{COD} / \mathrm{g} \mathrm{H}_{2} \mathrm{~S}$, it is possible to make an estimative of the percentage of the COD removed used for dye and sulfate reduction in each phase (Brás, 2004). Notice that the electrons anaerobically produced from the glucose ( 24 moles) are used for methane production, consumed in the decoloration of dye molecules (4 moles of electrons per mole of mono-azo dye) and sulfate reduction ( 8 moles of electron per mole of sulfate). In percentage terms, the COD necessary for the decoloration was less than $0.6 \%$ of the total electron flux produced. The mean consumption of glucose by the SRB increased with the sulfate concentration, from $4 \%$ of the removed COD in phase 2 , to $13 \%$ in phase 3 , to $16 \%$ in phase 4 . These values are related to the percentage of sulfate reduced, which was $88 \%$ in phase $2,75 \%$ in phase 3 , and $62 \%$ in phase 4 .

The characteristics of the treated effluent were dependent on feed composition, but the removal percentage of COD and color achieved are under those necessary for water reuse or discharge without further treatment. The mean values of COD, after dye and sulfate introduction, varied from 402 to $435 \mathrm{mg} / \mathrm{L}$, and the dye concentration was between 9 and $22 \mathrm{mg} / \mathrm{L}$ after treatment. However, the presence of aromatic amines resulting from azo dye cleavage is important and needs to be removed through further treatment.

\section{Conclusions}

The quality of the water recovered was limited by the low removal of the acetate buffer components. Because of this, the water reuse from these experiments could be tested in less-demanding operations than for the dyeing operations. The decrease in membrane performance in this study caused by the presence of buffering chemicals would indicate that other components of textile wastewaters, such as leveling agents, detergents, sizing chemicals, dyeing carriers, and fabric impurities, would restrict the use of nanofilters for treating composite textile wastewaters. However, there are many membrane systems capable of removing the buffering chemicals (Porter, 1996), so the data reported here would not limit the application of membranes, which are used in conjunction with anaerobic treatment. The concentrate produced had a COD-to-sulfate ratio of 2.1 and was treated by UASB, with no problem, and indicated that lower ratios could be treated successfully. Additional studies could be conducted to confirm this point. In this study, the sulfide concentration produced during UASB treatment did not cause either significant inhibition of microbes or improved color removal. However, the increased concentration of sulfate did cause a reduction in methane formation of $16 \%$, as expected.

The UASB reactor performance was good, but the treated effluent would require additional treatment to allow water reuse or to meet the environmental requirements for discharge imposed by national or EU legislation. Other treatment methods that may be considered for improving the quality of the effluent from the bioreactor are aerobic treatment, nanofiltration, reverse osmosis, or microfiltration. Some of these processes should be suitable for removing aromatic amines produced by UASB treatment and additional COD, sulfate, and dye removal.

Submitted for publication November 9, 2005; revised manuscript submitted June 7, 2006; revised manuscript submitted August 2, 2006.

\section{References}

American Public Health Association; American Water Works Association; Water Environment Federation (1992) Standard Methods for the Examination of Water and Wastewater, 17th ed.; American Public Health Association: Washington, D.C.

Aurich, C. W. (1995) Wastewater Treatment-Choosing the Right Membrane System. J. Soc. Dyers Colourists, 111 (6-7), 179-181.

Bhattacharya, S. K.; Uberoi, V.; Dronamraju, M. N. (1996) Interaction Between Acetate Fed Sulfate Reducers and Methanogens. Water Res., 30, 2239-2246.

Brandon, C. A.; Jernigan, D. A. (1981) Closed Cycle Textile Dyeing: FullScale Renovation of Hot Water by Hyperfiltration. Desalination, 39 (1), 301-310.

Brás, R. (2004) Anaerobic Biodegradation of Azo Dyes by Mixed and Methanogenic Cultures. Ph.D. Thesis, University of Beira Interior, Covilhã, Portugal (in Portuguese).

Choi, E.; Rim, J. M. (1991) Competition and Inhibition of Sulfate Reducers and Methane Producers in Anaerobic Treatment. Water Sci. Technol., 23, 1259-1264.

Colleran, E.; Pender, S. (2002) Mesophilic and Thermophilic Anaerobic Digestion of Sulphate-Containing Wastewaters. Water Sci. Technol., 45 (10), 231-235. 
European IPPC Bureau (2002) European IPPC Bureau in Integrated Pollution in Prevention and Control (IPPC), Reference Document on Best Available Techniques for the Textile Industry; European Commission: Seville, Spain.

Gomes, A. C.; Gonçalves, I. C.; de Pinho, M. N. (2005) The Role of Adsorption on Nanofiltration of Azo Dyes. J. Membr. Sci., 255 (1-2), 157-165.

Gonçalves, I. M. C.; Gomes, A. C.; Brás, R.; Ferra, M. I. A.; Amorim, M. T. P.; Porter, R. S. (2000) Biological Treatment of Effluents Containing Textile Dyes. J. Soc. Dyers Colourists, 116 (12), 393-397.

Koyuncu, I.; Topacik, D. (2002) Effect of Organic Ion on the Separation of Salts by Nanofiltration Membranes. J. Membr. Sci., 195 (2), 247-263.

Krull, K.; Döpkens, E. (2004) Recycling of Dyehouse Effluents by Biological and Chemical Treatment. Water Sci. Technol., 49 (4), 311-317.

Madsen, R. F. (1989) Hyperfiltration and Ultrafiltration in Plate and Frame Systems, 3rd ed.; Elsevier: New York.

Maillacheruvu, K. Y.; Parkin, G. F. (1996) Kinetics of Growth, Substrate Utilization and Sulfide Toxicity for Propionate, Acetate, and Hydrogen Utilizers in Anaerobic Systems. Water Environ. Res., 68, 1099-1106.

McCartney, D. M.; Olesziewicz, J. A. (1993) Competition Between Methanogens and Sulfate Reducers: Effect of COD:Sulfate Ratio and Acclimation. Water Environ. Res., 65, 655-664.

Méndez-Paz, D.; Omil, F.; Lema, J. M. (2003) Modeling of the Acid Orange 7 Anaerobic Biodegradation. Water Sci. Technol., 48 (6), 133-139.

Mulder, M. (1996) Basic Principles of Membrane Technology, 2nd ed.; Kluwer Academic Press: Boston, Massachusetts.

Peerters, J. M. M.; Boom, J. P.; Mulder, M. H. V. (1998) Retention Measurements of Nanofiltration Membranes with Electrolyte Solutions. J. Membr. Sci., 145 (2), 199-209.
Plumb, J. S.; Bell, J.; Stuckey, D. C. (2001) Microbial Population Associated with Treatment of an Industrial Dye Effluent in Anaerobic Baffled Reactor. Appl. Environ. Microbiol., 67, 3226-3235.

Porter, J. J. (1996) Environmental Chemistry of Dyes and PigmentsReduction of Textile Wastewater Using Automatic Process Control, Recycle, and Filtration, Reife, A., Freeman, H. S. (Eds.); John Wiley \& Sons: New York.

Porter, J. J.; Sargent, T. N. (1977) Waste Treatment vs. Waste Recovery. Textile Chemist Colorists, 9 (11), 269-272.

Rozzi, A.; Antonelli, M.; Arcari, M. (1999) Membrane Treatment of Secondary Textile Effluents for Direct Reuse. Water Sci. Technol., 40 (4-5), 409-416.

Schoeberl, P.; Brik, M.; Braun, R.; Fuchs, W. (2004) Treatment and Recycling of Textile Wastewater-Case Study and Development of a Recycling Concept. Desalination, 171 (2), 173-183.

van Lier, J. B.; Tilche, A.; Ahring, B. K.; Macarie, R.; Moletta, R.; Dohanyos, M.; Hulshoff Pol, L. W.; Lens, P.; Verstraete, W. (2001) New Perspectives in Anaerobic Digestion. Water Sci. Technol., 43 (1), $1-18$.

Vandevivere, P. C.; Bianchi, R.; Verstraete, W. (1998) Treatment and Reuse of Wastewater from the Textile Wet-Processing Industry: Review of Emerging Technologies. J. Chem. Biotechnol., 72 (4), 289-302.

Wiegant, W. M.; Lettinga, G. (1985) Thermophilic Anaerobic Digestion of Sugars in Upflow Anaerobic Sludge Blanket Reactors. Biotechnol. Bioeng., 27, 1603-1607.

Xu, Y.; Lebrun, R. E. (1999) Investigation of the Solute Separation by Charged Nanofiltration Membrane: Effect on $\mathrm{pH}$, Ionic Strength and Solute Type. J. Membr. Sci., 158 (1-2), 93-104. 